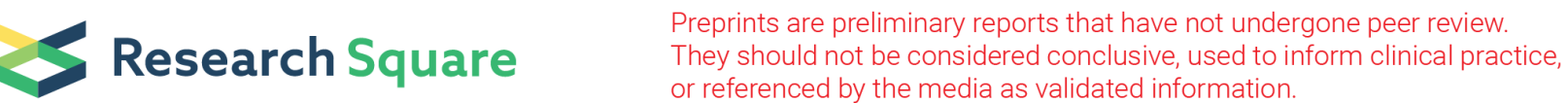

\section{Wall-Eyed Bilateral Internuclear Ophthalmoplegia Caused by Unilateral Subpontine Infarction: A Case Report}

\section{Jun Wang ( $D 948508843 @ Q Q . C O M)$}

Beijing Pinggu Hospital of Chinese Medicine https://orcid.org/0000-0002-4165-0750

\section{Chuan Yu}

Beijing Pinggu Hospital of Traditional Chinese Medicine

Yiyun Jiang

Beijing Pinggu Hospital of Traditional Chinese Medicine

\section{Xiang Li}

Beijing Pinggu Hospital of Traditional Chinese Medicine

\section{Yiyi Fang}

Beijing Pinggu Hospital of Traditional Chinese Medicine

\section{Case report}

Keywords: Wall-eyed bilateral internuclear ophthalmoplegia Stroke, Lower pons, Double vision

Posted Date: November 22nd, 2021

DOI: https://doi.org/10.21203/rs.3.rs-1078844/v1

License: (c) (i) This work is licensed under a Creative Commons Attribution 4.0 International License. Read Full License 


\section{Abstract}

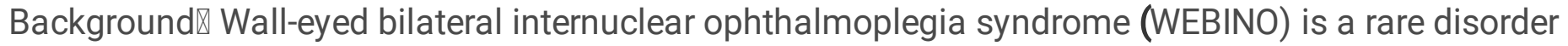
comprising bilateral exotropia, bilateral internuclear ophthalmoplegia, and impaired convergence. It is usually caused by a midbrain lesion.

Case presentation $₫$ We describe a rare case of WEBINO, with the lesion located in the lower pons, in a 69year-old man with acute ischemic stroke.

Conclusions $₫$ Our report alerts physicians to the possibility of bilateral WEBINO due to unilateral infarction.

\section{Background}

WEBINO is a rare syndrome comprising bilateral exotropia, bilateral internuclear ophthalmoplegia, and impaired convergence. It frequently accompanies diseases such as cerebral infarction, infection, demyelination, subarachnoid hemorrhage, hydrocephalus, brainstem cancer, and progressive supranuclear palsy. Most of the lesions causing WEBINO are located in the midbrain.

\section{Case Report}

A 69-year-old man with a history of hypertension, diabetes, and left hemiparesis caused by stroke sought medical help for vertigo and double vision. His left limb weakness was aggravated. On physical examination, both eyes exhibited primary gaze exotropia. Neither eye crossed the midline on attempted horizontal gaze. Bilateral internuclear ophthalmoplegia and impaired convergence were evident, but no nystagmus was noted. The right eye was in worse condition than the left (Figure 1); however, its pupillary light reflex was intact. Magnetic resonance imaging (MRI) showed an infarct on the right side of the lower pons (Figure 2). The patient was diagnosed with wall-eyed bilateral internuclear ophthalmoplegia (WEBINO) and treated with aspirin, clopidogrel, and atorvastatin. After a week, the left eye improved significantly, while the right eye abnormalities persisted (Figure 3).

\section{Discussion}

A literature search of PubMed using the keyword "wall-eye bilateral internuclear ophthalmoplegia" identified 19 cases ${ }^{[1-17]}$ in which lesion position were documented. Ten cases had lesions in the midbrain, four in the midbrain and pons, and five in the pons. ${ }^{[7.9 .13 .14 .16]}$ The oculomotor nucleus, which is located in the midbrain, was damaged in most patients. Based on these findings, most scholars attribute WEBINO to a combination of bilateral medial longitudinal fascicle (MLF) and medial rectus subnucleus (MRSN) damage. ${ }^{[18]}$

In three of the five cases in which the lesion occurred in the pons, the lesion was localized to the upper pons. ${ }^{[19-21]}$ The closeness of the upper pons to the midbrain might explain why lesions in the upper pons 
led to WEBINO. ${ }^{[22]}$ However, in our case, the lesion was located in the lower pons; moreover, there were no midbrain lesions. The infarction in the lower part of the pons damaged the MLF, but did not directly damage the MRSN. Thus, exotropia or a convergence disorder was not expected.

The cause of the subpontine lesions is unclear. There are only two previous reports ${ }^{[13.14]}$ on WEBINO caused by subpontine lesions, and no conclusive explanation was given in either article. Chen and Lin speculated that the lesion in their case involved the midbrain, although it was not obvious on MRI; ${ }^{[13]}$ hence, more evidence is required to prove this hypothesis. Since WEBINO is similar to wall-eyed monocular internuclear ophthalmoplegia (WEMINO), we searched PubMed using "WEMINO" and "lower pons" or "subpontine" as keywords. Only two cases were retrieved: one did not address the cause of the WEBINO ${ }^{[22]}$, whereas the other implicated abnormal vestibular signals to the MRSN, with resultant muscle tone asymmetry and ocular abduction toward the injured side. ${ }^{[23]}$ Both the latter case and the present case included vertigo, which was likely related to the presence of the vestibule. Hence, the neural pathways between the pons and midbrain need to be further studied.

Most lesions that cause WEBINO are located in the midline. In the present case, the lesion was in the right pons and did not cross the midline. Unilateral pons infarction leading to WEBINO is rare, with only one previous case. ${ }^{[13]}$ The infarct in our case and the previous case was positioned proximal to the midline; in the previous case, parts of the infarct extended slightly beyond the midline. Because the infarct area and its contralateral side are both supplied by the basilar artery pontine branch, we believe that the infarction on the right side impaired the blood supply to the left side. Owing to its proximity to the MLF on both sides, the infarct on one side likely affected the contralateral MLF.

Our patient had a severely affected right eye which, unlike his left eye, did not rapidly recover. The patient in the study by Chen and Lin also showed mild symptoms on the contralateral side and severe symptoms on the ipsilateral side. ${ }^{[13]}$ Since their patient died, recovery on both sides was not verified.

WEBINO is a rare ocular movement disorder. Unilateral infarction rarely leads to bilateral WEBINO. Some explanations have been proposed, although none have been confirmed. Thus, this disease needs further investigation.

\section{Declarations}

\section{Ethics approval and consent to participate}

Not applicable

\section{Consent for publication}

Written informed consent was obtained from the patient for publication of this case report and accompanying images. A copy of the written consent is available for review by the Editors-in-Chief of this journal 
Availability of data and materials

All data generated or analyzed during this study are included in this published article and its supplementary information files

\section{Competing interests}

The authors declare that they have no competing interests

\section{Funding}

NONE

\section{Authors' contributions}

JW, $C Y$ and $Y J$ analyzed and interpreted the patient data together. $X L$ and YF searched the previous literature and find relevant cases JW was the major contributor in writing the manuscript. All authors read and approved the final manuscript.

\section{Acknowledgements}

Not applicable

\section{References}

1. Papageorgiou E. Tsironi EE, Androudi S, et al. Teaching video neuroimages: pulsatile proptosis and wall-eyed bilateral internuclear ophthalmoplegia. Neurology. 2018; 90(17):e1542-e1543.

2. Man BL, Chi MS, Fu YP. Wall-eyed bilateral internuclear ophthalmoplaegia (WEBINO) from a paramedian mesencephalic infarct. BMJ Case Rep. 2015; 2015:bcr2014207240.

3. Ljevak J, Mismas A, Poljakovic Z, et al. Bilateral ptosis with wall-eyed bilateral internuclear ophthalmoplegia and vertical gaze paralysis. Neurol Sci. 2015; 36(3):473-475.

4. Agarwal A, Vyas S, Banzal S, et al. Wall-eyed bilateral internuclear ophthalmoplegia. Neurol India. 2015; 63(3):444-446.

5. Rodriguez Calvo de Mora M, Rodriguez Moreno G, Espana Contreras M. Webino syndrome caused by meningovascular syphilis. A rare entity with an unexpected cause. Arch Soc Esp Oftalmol. 2014; 89(5):199-202.

6. Nakajima N, Ueda M, Katayama Y. Brainstem infarction for wall-eyed bilateral internuclear ophthalmoplegia syndrome and vertical one-and-a-half syndrome. J Stroke Cerebrovasc Dis. 2014; 23(4):e291-293.

7. Mathis $T$, Ducray F, Tilikete $C$, et al. Pontine infarction responsible for wall-eyed bilateral internuclear ophthalmoplegia syndrome. Neurol Clin Pract. 2014; 4(6):524-525. 
8. Chakravarthi S, Kesav P, Khurana D. Wall-eyed bilateral inter nuclear ophthalmoplegia with vertical gaze palsy. QJM. 2014; 107(2):165.

9. Sakamoto $Y$, Kimura K, Iguchi Y, et al. A small pontine infarct on DWI as a lesion responsible for walleyed bilateral internuclear ophthalmoplegia syndrome. Neurol Sci. 2012; 33(1):121-123.

10. Beh SC, Frohman EM. WEBINO and the return of the king's speech. J Neurol Sci. 2012; 315(1-2):153155.

11. Sierra-Hidalgo F, Moreno-Ramos T, Villarejo A, et al. A variant of WEBINO syndrome after top of the basilar artery stroke. Clin Neurol Neurosurg. 2010; 112(9):801-804.

12. Kim JS, Jeong SH, Oh YM, et al. Teaching neuroimage: wall-eyed bilateral internuclear ophthalmoplegia (WEBINO) from midbrain infarction. Neurology. 2008; 70(8):e35.

13. Chen $\mathrm{CM}$, Lin SH. Wall-eyed bilateral internuclear ophthalmoplegia from lesions at different levels in the brainstem. J Neuroophthalmol. 2007; 27(1):9-15.

14. Uzawa A, Takeda Y, Kuwabara S. Wall-eyed bilateral internuclear ophthalmoplegia by ischemic stroke. Neurologist. 2020;25(3):82-84.

15. Vázquez-Justes D, Martín-Cucó A, Gallego-Sánchez Y, et al. WEBINO syndrome (wall-eyed bilateral internuclear ophthalmoplegia) secondary to ischemic stroke, about a case. Arch Soc Esp Esp Oftalmol (Engl Ed). 2020; 95(4):205-208.

16. Im K, Ju H, Lee M, et al. A case report of wall-eyed bilateral internuclear ophthalmoplegia with bilateral facial palsy. J Stroke Cerebrovasc Dis. 2020; 29(11):105139.

17. Jo YS, Hong JY, Kim SY, et al. Wall-eyed bilateral internuclear ophthalmoplegia (WEBINO) in a patient with a unilateral midbrain infarction. Neurologist. 2021; 26(4):153-155.

18. Ljevak J, Mišmaš A, Poljaković Z, et al. Bilateral ptosis with wall-eyed bilateral internuclear ophthalmoplegia and vertical gaze paralysis. Neurol Sci. 2015; 36(3):473-475.

19. Papageorgiou E, Tsironi EE, Androudi S, et al. Teaching video neuroimages: pulsatile proptosis and wall-eyed bilateral internuclear ophthalmoplegia. Neurology. 2018; 90(17):e1542-e1543.

20. Mathis T, Ducray F, Tilikete $C$, et al. Pontine infarction responsible for wall-eyed bilateral internuclear ophthalmoplegia syndrome. Neurol Clin Pract. 2014; 4(6):524-525.

21. Sakamoto Y, Kimura K, Iguchi Y, et al. A small pontine infarct on DWI as a lesion responsible for walleyed bilateral internuclear ophthalmoplegia syndrome. Neurol Sci. 2012;33(1):121-123.

22. Tsuda $H$, Kamata $K$, Tanaka $K$, et al. WEMINO syndrome with skew deviation and facial palsy. Intern Med. 2011; 50(20):2435-2436.

23. Ceballos-Lizarraga R, Palomino-Díaz C, Romero-Figueroa, JA. Wall-eyed monocular internuclear ophthalmoplegia (WEMINO) and Millard-Gubler syndromes in a patient with isolated pontine infarction: topographic, oculomotor, and radiological analysis of two very uncommon conditions. Case Rep Neurol. 2019; 11(2):230-237.

\section{Figures}



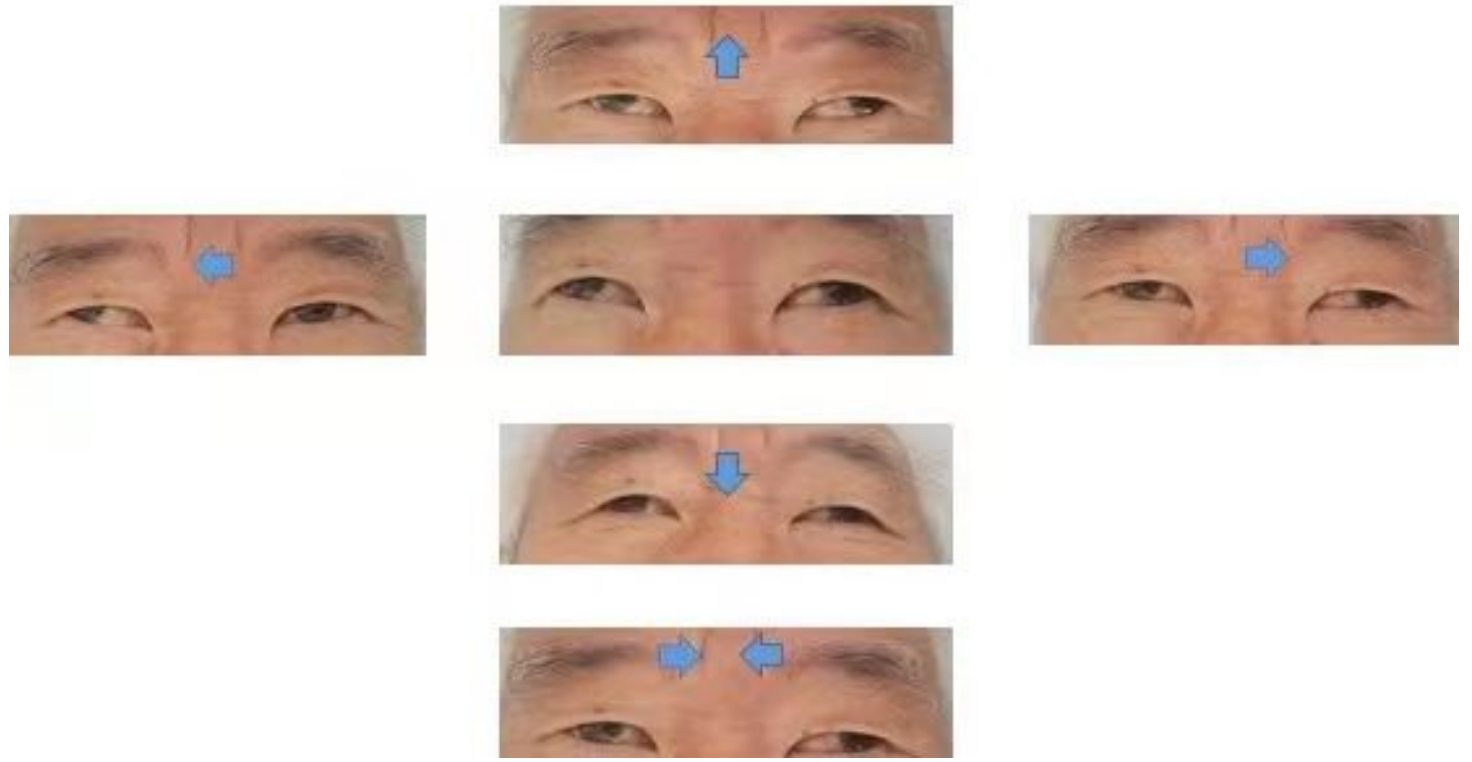

\section{Figure 1}

Screenshots of the eye movements before treatment. The arrows indicate the direction of the movement. 

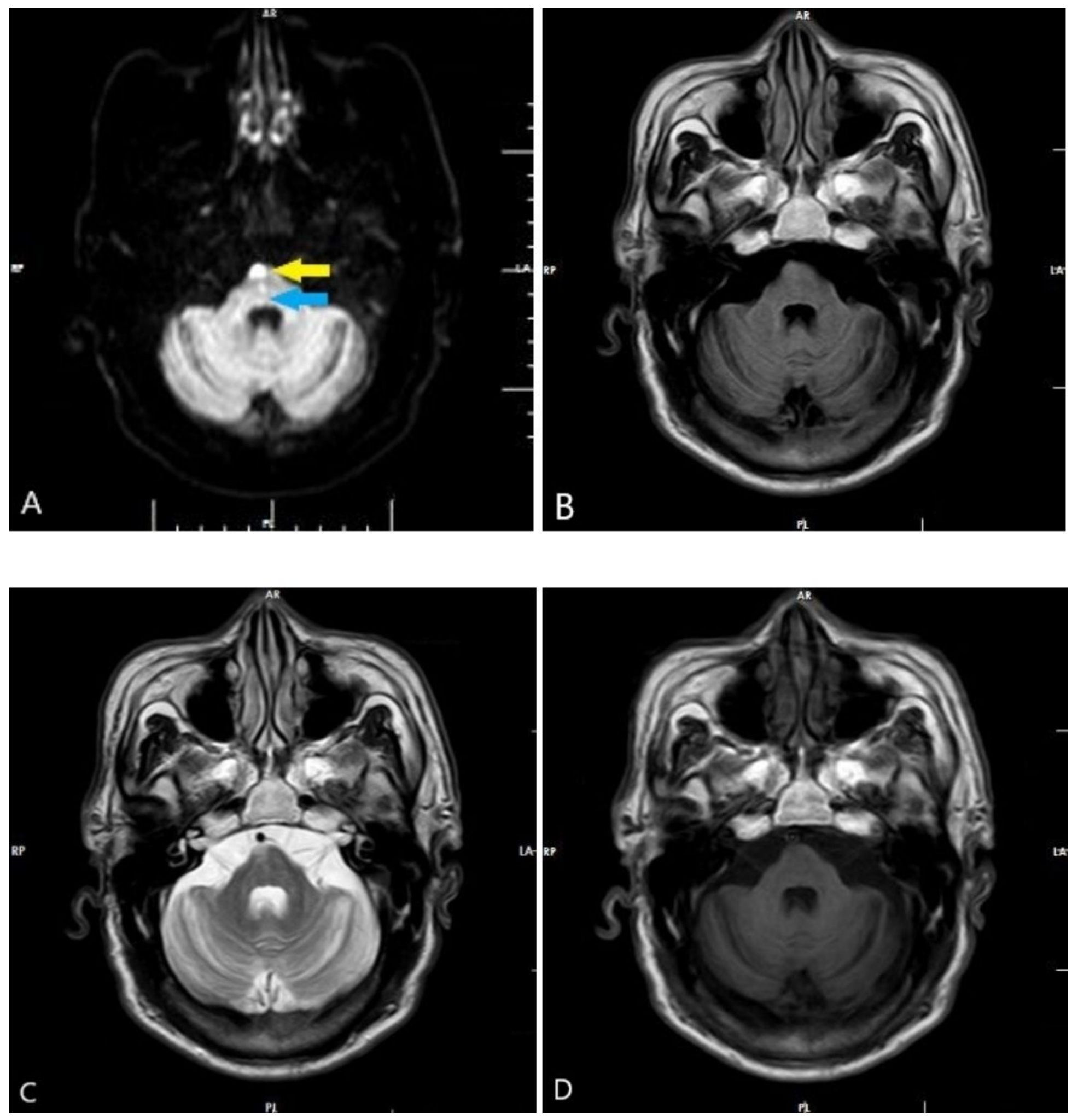

\section{Figure 2}

Magnetic resonance imaging findings of unilateral subpontine infarction. High signal intensity is seen on diffusion-weighted imaging (A), T2-weighted imaging (B), and fluid-attenuated inversion recovery imaging (C), and a low signal intensity is seen on T1-weighted imaging (D). 

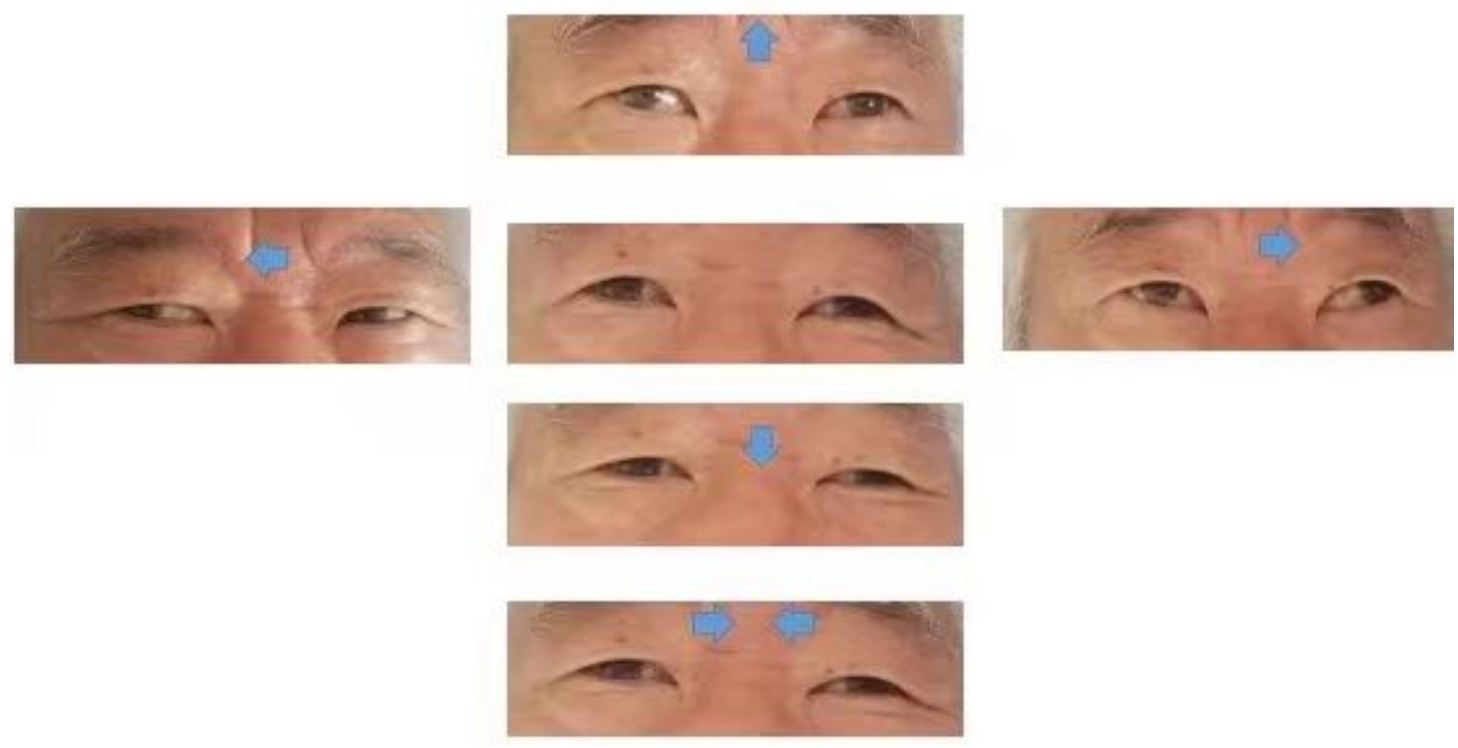

Figure 3

Screenshots of the eye movements after treatment. The arrows indicate the direction of the movement. 